
\title{
Migration and Localization
}

\author{
T.E. Starzl, N. Murase, A.W. Thomson, M. Trucco, and A. Rao
}

$\mathrm{T}^{\mathrm{H}}$

HE PURPOSE of this communication is to describe a recently delineated principle of immunology ${ }^{1}$ that can be summarized in one line: immunity, or alternatively tolerance, to any antigen is governed by the migration and localization of that antigen. This concept, which has been developed with transplantation models ${ }^{2-4}$ and from observations after clinical and experimental infections ${ }^{5-7}$ has been described elsewhere in more detail. ${ }^{1}$ Here, we will be concerned mainly with the relation between donor leukocyte chimerism and transplantation tolerance, focusing at first on clinicopathologic observations in transplant recipients made in 1991-1992 that prompted reconsideration of a number of long held convictions.

\section{HISTORICAL CLUES IN TRANSPLANTATION}

The most important new finding reported in 1992 was the presence of multilineage donor leukocyte microchimerism in the blood, skin, lymph nodes, and other tissues of organ allograft recipients up to 30 years after successful transplantation. ${ }^{2-4}$ The persistence of the disseminated donor leukocytes for this long implied (as was subsequently proved $^{8.9}$ ) that precursor or stem cells are included in the burst of donor leukocytes that briefly constitute $1 \%$ to $20 \%$ of the recipient circulating mononuclear cells after organ transplantation (Fig 1, upper panel). Although the number of these donor cells is greatest with transplantation of the intestine or liver, ${ }^{10,11}$ the same events on a smaller scale occur after transplantation of organs like the kidney and heart. $^{12}$

Another change during the early postoperative period is disappearance of the resident donor mononuclear leukocytes from the graft and their replacement by recipient cells of the same lineages (Fig 1, lower). Although this was observed in hepatic allografts nearly 30 years ago, ${ }^{13}$ it was assumed at first to be a unique feature of liver transplants. After the same changes were found in intestinal allografts, ${ }^{11,14}$ evidence quickly accrued that this was a generic phenomenon; ie, it occurred in all successfully transplanted organs. ${ }^{3,15}$

These discoveries, showing that both the "accepted" allograft and recipient became genetic composites, suggested an explanation for two enigmatic observations reported for the first time in $1963^{16}$ that had allowed the development of organ transplantation as a practical and reproducible clinical service. First, kidney rejection developing in patients immunosuppressed with azathioprine could be consistently reversed with large doses of prednisone. The second, and more important, observation was that renal allografts self-induced variable degrees of donorspecific tolerance, manifested by the subsequent ability to reduce immunosuppression to below doses that had been unable to prevent or control rejection at the outset. ${ }^{16}$ It was obvious that a host-versus-graft (HVG) immune reaction gathered strength at first despite anti-rejection therapy, but then collapsed with temporarily intensified immunosuppression. The same events were soon-documented after liver transplantation ${ }^{17,18}$ and eventually with all other kinds of organ allografts. They can be observed. in many animal models without the need for immunosuppression (summarized in Starzl et $\mathrm{al}^{4}$ ), most commonly when the liver is the transplanted organ. ${ }^{19}$

\section{THE HISTORICAL BRIDGE TO INFECTION}

Early workers in transplantation recognized the resemblance of allograft rejection to the response against infections associated with delayed hypersensitivity, as exemplified by tuberculosis. ${ }^{20,21}$ With the demonstration of the MHC-restricted mechanisms of adaptive infectious immunity in $1973,{ }^{22-25}$ it seemed obvious that allograft rejection must be the physiologic equivalent of the response to this kind of infection. Microorganisms that generate such an adaptive immune response are generally intracellular, and have no or low cytopathic qualities. Although MHC-restricted host cytolytic $\mathrm{T}$ lymphocytes recognize only infected cells, elimination of all the infected cells could disable or even kill the host. Consequently, mechanisms have evolved that can temper or terminate the immune response, allowing both host and pathogen to survive..$^{5-7}$

From the Thomas E. Starzl Transplantation Institute and the Departments of Surgery (T.E.S., N.M., A.W.T., A.R.), and Pediatrics, University of Pittsburgh Medical Center, Pittsburgh, Pennsylvania.

Aided by Project Grant No. DK 29961 from the National Institutes of Health, Bethesda, Maryland.

Address reprint requests to Thomas E. Starzl, MD, PhD, Department of Surgery, 3601 Fifth Avenue, 5C Falk Clinic, University of Pittsburgh, Pittsburgh, Pennsylvania, 15213. 

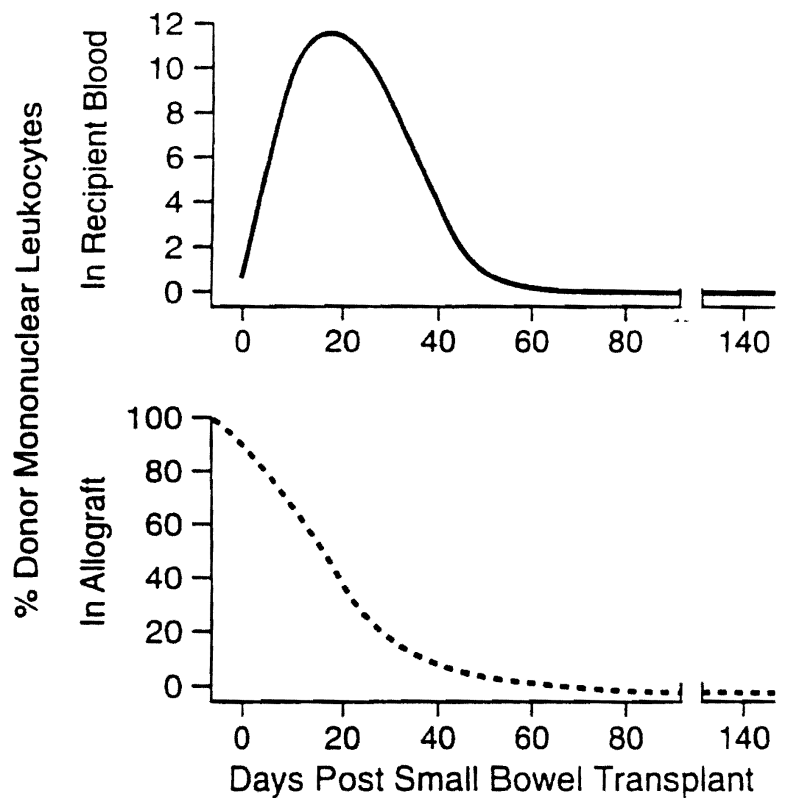

Fig 1. The dynamic events after transplantation of all organs, exemplified by intestinal engraftment. Upper panel. The surge of migratory donor mononuclear leukocytes in the recipient blood during the first 2 or 3 weeks posttransplantation. Lower panel. The contemporaneous disappearance of the passenger leukocytes from the allograft; these are replaced by recipient cells of the same lineages (schematically redrawn from data in Iwaki et $\mathrm{al}^{11}{ }^{11}$ ).

The highly variable clinical manifestations of these mechanisms can be illustrated by the different outcomes that may follow an infection with disseminated non-cytopathic microorganisms (eg, the common hepatitis viruses). In one scenario, the pathogen (antigen) load may rapidly increase during the so-called latent period, but then be dramatically and efficiently reduced by antigen-specific effector T-cells. Following control of the infection, the cytotoxic T lymphocytes (CTL) subside (Fig 2, left panel). The events are similar to those of irreversible organ rejection in the unmodified or ineffectively treated recipient (Fig 2, subscript to left panel). Alternatively, however, such infections may lead to a continuously high antigen load and an antigen specific immunologic collapse (Fig 2, second panel). The consequent asymptomatic carrier state is equivalent to unqualified acceptance of an allograft. This kind of result, including independence from immunosuppression, is rarely achieved by organ recipients and is usually associated with good HLA compatibility.

Between these two extremes of protective immunity and a carrier state, a persistent infectious agent may induce an unrelenting immune response that results in serious immunopathology (eg, chronic active hepatitis with a $\mathrm{B}$ or $\mathrm{C}$ virus infection). This is equivalent to chronic rejection after liver transplantation (Fig 2, right), or uncommonly graft-versushost disease (GVHD; see later). The result as a practical matter in the overwhelming majority of organ recipients is chronic rejection which may range from aggressive to indolent, despite the best immunosuppression available today.

\section{TOLERANCE: THE BIOLOGIC SAFETY VALVE}

Under both infectious and transplant circumstances, only two mechanisms are needed to explain the compromise outcomes shown in the second and third panels of Fig 2 which allow co-existence of live antigen and the host. One is clonal exhaustion leading to clonal deletion. The other is immune indifference. Although these two mechanisms will

$$
-\quad \text { IR }>V
$$

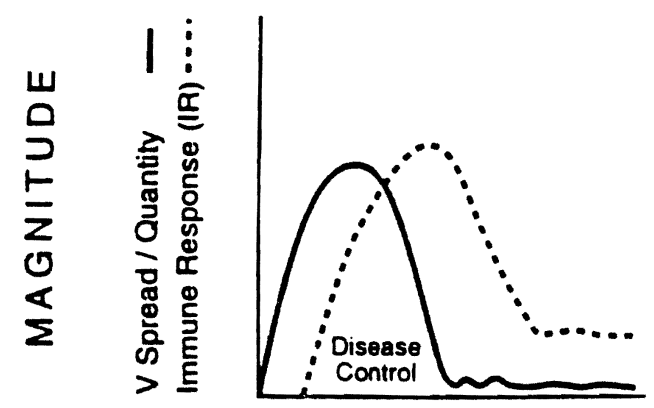

Transplant Analogue:
Acute graft rejection (or GVHD)

IR $\ll V$

(Exhaustion / deletion of immune response)

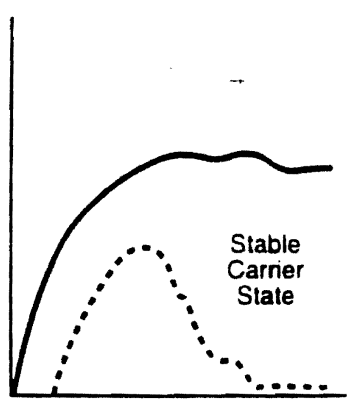

Stable graft acceptance

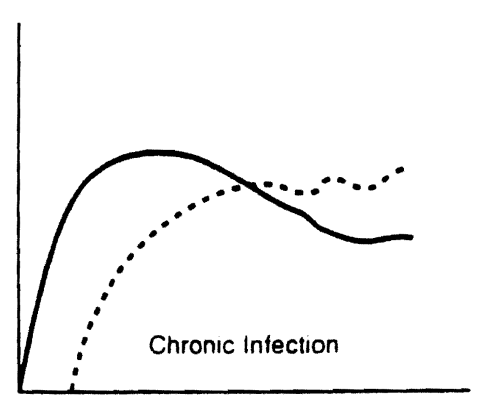

Chronic graft rejection ( or GVHD)

\section{TIME}

Fig 2. Variable outcomes after infection with widely disseminated non-cytopathic viruses (or other microorganisms) and analogies (in the subscripts) to organ and bone marrow transplantation. The horizontal axis denotes time, and the vertical axis shows the viral load ( $v$, solid line), and the host immune response ( $\mathrm{R}$, dashed line). 


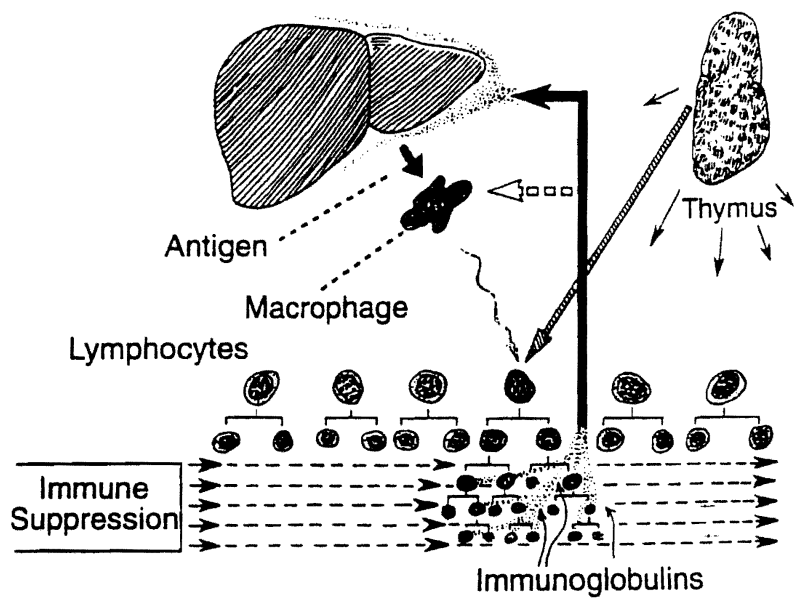

Fig 3. Hypothesis published in 1969 of allograft acceptance by clonal exhaustion. Antigen presentation was depicted via the macrophages rather than by the dendritic cells (which had not yet been described). A gap in this hypothesis was the failure to stipulate the location of the immune activation (by permission of W.B. Saunders $\mathrm{Co}^{28}$ ).

be considered separately, they tend to be mutually reinforcing. Both are regulated by antigen migration and localization.

\section{Clonal Exhaustion/Deletion}

The exhaustion and deletion of an antigen specific clone was postulated as early as 1959-1960 to explain the acquisition of tolerance in animal models to heterologous protein (with the aid of 6-mercaptopurine, ${ }^{26}$ ) and to allogeneic splenocytes (without the need for immunosuppression ${ }^{27}$ ). Clonal exhaustion also was invoked at an early time to explain organ allograft acceptance, ${ }^{28,29}$ as shown in the illustration and caption reproduced in Fig 3. In this figure, which was first published in 1969, induction of the activated clone by alloantigen was depicted via host macrophages rather than by dendritic cells which would not be described until 4 years later. ${ }^{30}$

The Eclipse of Clonal Exhaustion. Despite circumstantial evidence of its existence as a tolerogenic mechanism (summarized in Steinman and Cohn ${ }^{31}$ and Sterzl and Silverstein $^{32}$ ), clonal exhaustion disappeared from the literature between 1970 and 1990, ostensibly because it was only a theory. Since 1990, however, clonal exhaustion/deletion has been formally demonstrated in many infectious, transplantation, and other models. ${ }^{33-38}$ A subpopulation of $\mathrm{T}$ cells is induced by the antigen within a few days, end-differentiates to effector cells, and disappears.

Death of the activated cells by apoptosis has been demonstrated in a mouse transplantation model, ${ }^{37}$ possibly due to interleukin deprivation. and associated with telemere shortening. ${ }^{39}$ Although clonal exhaustion is the most efficient way to eliminate maturing self-reactive $T$ cells in ontogeny and throughout the life of many higher vertebrates, purging of $\mathrm{T}$ cells (and also apparently $\mathrm{B}$ cells) also occurs in the peripheral lymphoid organs. The peripheral sites may be the principal site of clonal deletion after successful transplantation in humans. ${ }^{4}$

Altemative Tolerogenic Mechanisms. Although lack of proof contributed to the dismissive reception of clonal exhaustion, a more pervasive factor in the context of transplantation immunology was a lack of understanding about the role of the organ's "passenger leukocytes." These donor cells of bone marrow origin have been known for more than three decades to be the principal immunogenic component of allografts. ${ }^{40,41}$ Because they disappear from successfully transplanted organs, ${ }^{11,14,15,40-43}$ it was assumed until recently that they had been selectively destroyed by the recipient immune system, with selective sparing of the specialized parenchymal cells.

As a corollary, organ allograft acceptance was assumed to take place by fundamentally different mechanisms than the chimerism-dependent acquired neonatal tolerance of Billingham, Brent, and Medawar. ${ }^{44}$ Proposed chimerism-exclusionary mechanisms have included suppressor, veto, and other immune regulatory cells; cytokine profile changes; various antibodies; and failure of delivery of a second (costimulatory) signal following primary antigen presentation. Contrary to these hypotheses, the discovery of microchimerism in organ recipients"made it possible, in 1992, to explain allograft acceptance by “... [widespread] responses of co-existing donor and recipient immune cells, each to the other, causing reciprocal clonal expansion, followed by peripheral clonal deletion."2

The Double Immune Reaction. This feature distinguishes the allograft response from the single immune reaction induced by an infection. ${ }^{1}$ If some degree of reciprocal clonal exhaustion is not induced and maintained (requiring an umbrella of immune suppression in humans), one cell population usually will destroy the other, or both may be destroyed together. Following organ transplantation, the dominant host system usually rejects the graft (Fig 4). However, serious or lethal GVHD is not rare after transplantation of leukocyte-rich organs such as the liver. ${ }^{3}$

In contrast, the recipient cyto-ablation used in preparation for bone marrow transplantation transfers dominance to the donor system (Fig 5). Consequently, GVHD is the most common complication in bone marrow recipients, but the graft may be rejected instead, or simultaneously.

The Governance of Clonal Exhaustion. Migration of spreading non-cytopathic microorganisms to host lymphoid organs, and localization there, are well known to be critical in initiating and sustaining protective immune activation..$^{5-7,45}$ The similar lymphoid-oriented traffic of passenger leukocytes $^{46-+8}$ is equally acknowledged to be the essential basis of host allosensitization. Carried one step further to clonal exhaustion, it also is the means by which specific immunologic tolerance is induced.

Immune Indifference

Although clonal exhaustion/deletion is the seminal mechanism of tolerance, survival of either allo- or infectious 


\section{Organ Transplantation}

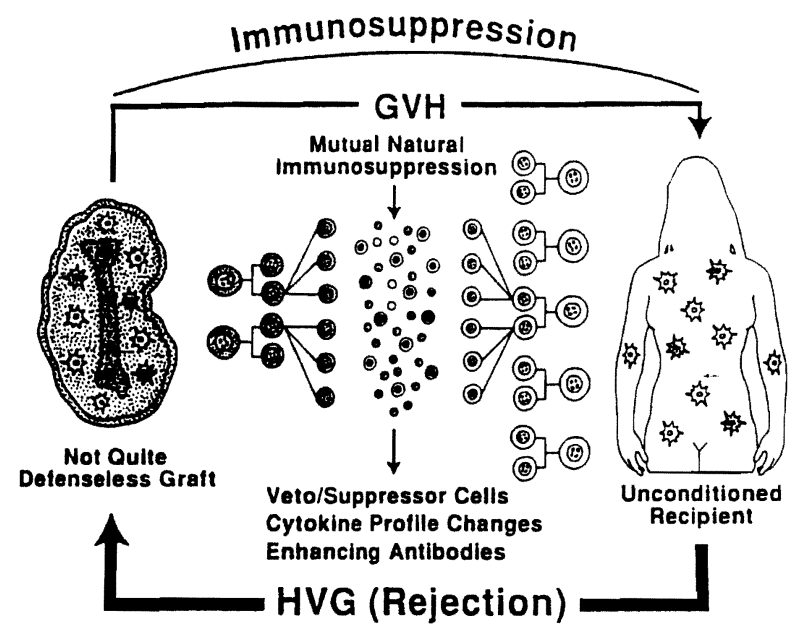

Fig 4. Organ transplantation, seen as a bidirectional and mutually canceling immune reaction that is predominantly host versus graft in most cases.

antigen may be promoted by a second nontolerogenic mechanism, called "immune indifference." 5,7 Like clonal exhaustion, immune indifference is controlled by antigen migration and localization.

Primary. Pure examples of de novo immune indifference are provided by the rabies and wart viruses which elicit little or no immune response (Fig 6), simply by avoiding migration through, or to, host lymphoid organs. This has been mimicked in numerous transplant models by depletion of donor leukocytes from allografts. Graft survival is thereby prolonged (subscript of Fig 6). However, tolerance is not induced, as shown by the fact that rejection can be readily precipitated with an injection of donor leukocytes. ${ }^{41,49,50}$

\section{Bone Marrow Transplantation}

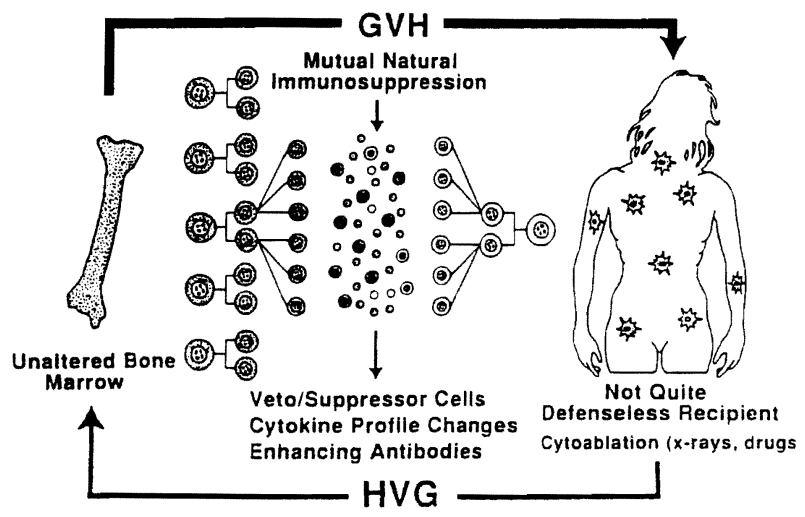

Fig 5. Bone marrow transplantation. Because the recipient is cytoablated, the immune reaction is predominantly graft vs. host, resulting in a mirror image of that shown in Fig 4.

\section{$\checkmark$ Unopposed (Immunologically Ignored)}

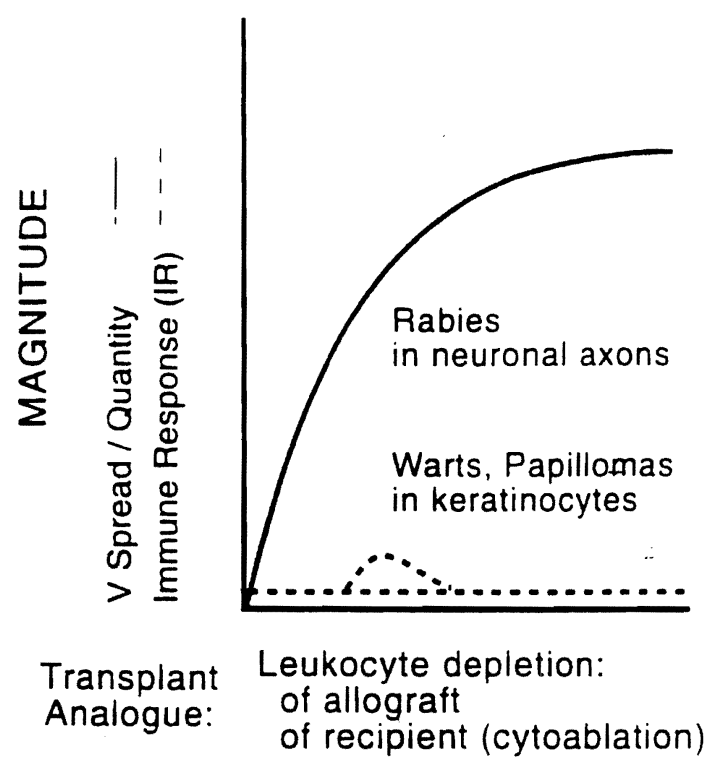

TIME

Fig 6. Immune indifference when an infectious agent does not migrate through or to an organized lymphoid collection. Transplantation analogs are shown in the subscript. The horizontal and vertical axes are as in Fig 2. Note the minimal or absent host immune response (IR, dashed line).

Secondary. Pristine examples of immune indifference are not seen in the usual setting of clinical organ transplantation. Nevertheless, immune indifference can evolve secondarily. As also occurs with microorganisms following a widespread noncytopathic infection, ${ }^{7,51}$ migratory donor leukocytes that have not been eliminated by passage through lymphoid organs may leave the lymphoid compartment, having induced various stages of incomplete and/or reversible antigen specific exhaustion. In experimental organ transplant models, this begins after about 2 weeks, and by 100 days, the most prominent donor leukocyte population has shifted from lymphoid sites to nonlymphoid sites (eg, skin and heart). ${ }^{52}$ Maintenance clonal exhaustion apparently occurs subsequently by leakage of donor leukocytes from the non-lymphoid to the lymphoid compartment (Fig 7).

The balance that develops between destructive and nondestructive immunity as the result of lymphoid/non-lymphoid leakage has been difficult to quantitate in transplantation models. However, a stable equilibrium has been demonstrated by Ohashi, Zinkernagel, et al in transgenic mouse preparations. ${ }^{53.54}$ In these models, pancreatic islets expressing viral antigens are not destroyed by low level CTL activity, but are rejected with resulting diabetes by the induction of high virus-specific reactivity. 


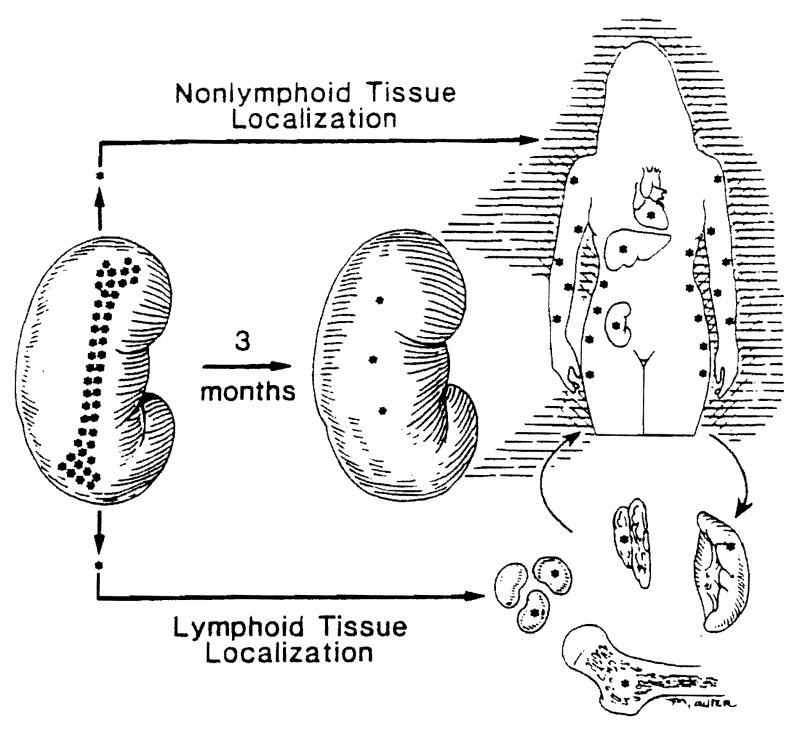

Fig 7. Reconstruction of events after organ transplantation, epitomized by the heart with its "passenger leukocyte" component depicted as a bone silhouette. Most, but not all, of the donor leukocytes leave the graft and are largely replaced by recipient cells of the same lineages. The early migration of the donor leukocytes is oriented to the host lymphoid organs, but by 100 days, the surviving donor cells have largely relocated to the non-lymphoid tissues (here shown as skin and native heart). Subsequent leakage between the lymphoid and non-lymphoid compartments is thought to maintain clonal exhaustion (see text).

In a further exploitation of similar transgenic models, Ehl, Zinkernagel et al have shown the essential role of antigen persistence in the maintenance of tolerance. ${ }^{55}$ Tolerance to transgenic skin grafts expressing the viral antigen (gp33) of the lymphocytic choriomeningitis virus could be induced by pretreatment of recipients with gp33 but it could not be maintained by the gp 33 expressed by outlying skin graft. In contrast, tolerization with gp33expressing, mobile, and self-renewing spleen cells (ie, donor splenocyte chimerism) permanently protected the transgenic skin. By analogy, the disappearance of microchimerism in an organ recipient presages loss of the outlying graft to chronic or acute rejection. ${ }^{56.57}$ In the model of Ehl et $\mathrm{al},{ }^{55}$ this was associated with thymus dependent recovery of precursor CTL.

\section{THE COLLABORATION OF CLONAL EXHAUSTION AND IMMUNE INDIFFERENCE}

With clonal exhaustion and immune indifference in combination, both regulated by the migration and localization of antigen, the four inter-related events shown schematically in Fig 8 must occur close together if organ transplantation is to succeed: double acute clonal exhaustion, maintenance clonal exhaustion which waxes and wanes, and loss of graft immunogenicity as the organ is depleted of its passenger leukocytes.

The significance of the microchimerism observed at the

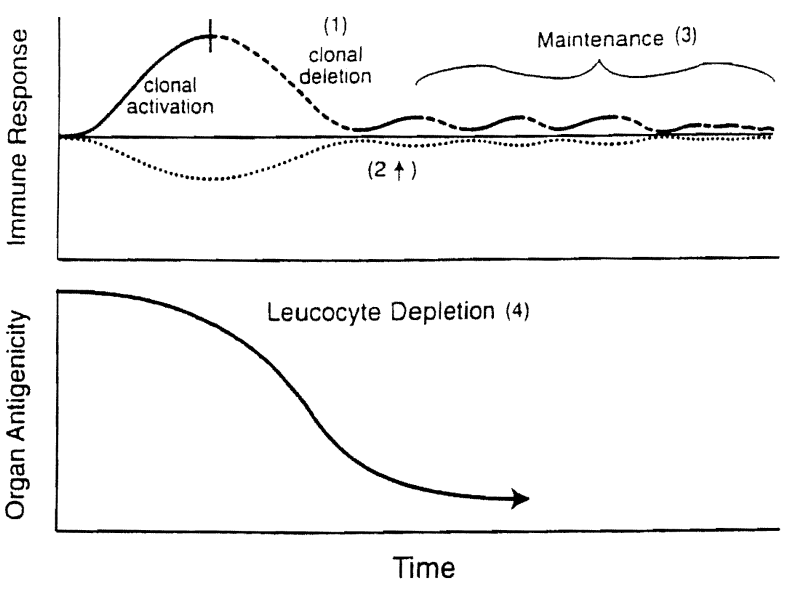

Fig 8. The four events that occur in close temporal approximation when there is successful organ engraftment: above, double acute clonal exhaustion ${ }^{1,2}$ and subsequent maintenance clonal exhaustion ${ }^{3}$ plus, below, loss of organ immunogenicity due to depletion of the graft's passenger leukocytes. ${ }^{4}$

end of this process has been questioned (summarized in Wood and $\mathrm{Sachs}^{58}$ ) because, as we also have emphasized, ${ }^{2-4,59}$ donor leukocytes may be detectable during rejection, and are often not detectable in individual b̆lood or tissue samples in patients bearing stable allografts. These observations are readily fitted into the concept that "... Donor leukocyte chimerism is a prerequisite for but not synonymous with and not a consequence of, organ allograft acceptance." ${ }^{1}$ This conclusion applies equally to macro and microchimerism.

\section{BONE MARROW VERSUS ORGAN TRANSPLANTATION}

Conventional bone marrow transplantation (Fig 5 ) is only a mirror image of the events after organ transplantation (Fig 4 ), with the same governance of the immune events by antigen migration and localization. Although pretransplant cyto-ablation renders the recipient subject to GVHD, the host leukocytes are not all eliminated. ${ }^{60}$ The weak hostversus-graft reaction mounted by the remaining recipient cells, and the parallel GVH reaction of the donor cells can eventually result in reciprocal tolerance.

\section{SELF/NON-SELF DISCRIMINATION}

Because the fetus possesses very early $T$ cell immune function, ${ }^{31,61,62}$ the ontogeny of self/non-self discrimination during fetal development can be explained by the same mechanisms as acquired tolerance in later life. Autoimmune diseases then reflect unacceptable post-natal perturbations of the prenatally established localization of self antigens in non-lymphoid versus lymphoid compartments.

\section{XENOTRANSPLANTATION}

There is no MHC-restricted safety valve for cytopathic microorganisms which are typically extracellular and generate the full resources of the innate as well as the adaptive 
Table 1. Effectors Involved in Response to Cytopathic Parasites and Discordant Xenografts

\begin{tabular}{lc}
\hline The First Line of Defense & Non-Specific or Less Specific Effectors \\
\hline Interferons & Complement \\
Macrophages & Early interleukins \\
$\gamma / \delta T$ cells & Phagocytes \\
Natural killer $(N K)$ cells & \\
B cells & \\
\hline
\end{tabular}

immune system. ${ }^{1,5}$ An uncontrollable innate immune response involving the effectors shown in Table 1 is provoked by discordant xenografts expressing the Gal- $\alpha \mathrm{Gal}$ epitope, an epitope which also is found on numerous cytopathic bacteria, protozoa, and viruses. The clinical use of such discordant animal donors will require changing the xenogeneic epitope to one that mimics a non-cytopathic profile, or else elimination of the xenogeneic epitope. ${ }^{1}$

\section{REFERENCES}

1. Starzl TE, Zinkernagel RM: New Engl J Med (in press)

2. Starzl TE, Demetris AJ, Murase N, et al: Lancet 339:1579, 1992

3. Starzl TE, Demetris AJ, Trucco M, et al: Hepatology 17:1127, 1993

4. Starzl TE, Demetris AJ, Murase N, et al: Immunol Today 17:577, 1996

5. Zinkernagel RM: Science 271:173, 1996

6. Zinkernagel RM, Bachmann MF, Kundig TM, et al: Annu Rev Immunol 14:333, 1996

7. Zinkernagel RM, Ehl S, Aichele $P$, et al: Immunol Rev 156:199, 1997

8. Murase N, Starzl TE, Ye Q, et al: Transplantation 61:1, 1996

9. Taniguchi H, Toyoshima T, Fukao K, et al: Nature 2:198, 1996

10. Grant. D, Wall W, Mimeault R, et al: Lancet 335:181, 1990

11. Iwaki Y, Starzl TE, Yagihashi A, et al: Lancet 337:818, 1991

12. Schlitt HJ, Hundrieser J, Hisanaga M, et al: Lancet 343 : 1469, 1994

13. Kashiwagi N, Porter KA, Penn I, et al: Surg Forum 20:374, 1969

14. Murase N, Demetris AJ, Matsuzaki T, et al: Surgery 110:87, 1991

15. Starzl TE, Demetris AJ, Trucco M, et al: Transplantation $55: 1272,1993$

16. Starzl TE, Marchioro TL, Waddell WR: Surg Gynecol Obstet 117:385, 1963

17. Starzl TE, Marchioro TL, Von Kaulla KN, et al: Surg Gynecol Obstet 117:659, 1963

18. Starzl TE, Marchioro TL, Porter KA, et al: Surgery 58:131, 1965

19. Calne RY, Sells RA, Pena JR, et al: Nature 223:472, 1969

20. Lawrence HS: Physiol Rev 39:811, 1959

21. Medawar PB: In The Harvey Lectures, Series 52. New York: Academic Press; 1956, p 144

22. Doherty PC, Zinkernagel RM: Nature 256:50, 1975

23. Zinkernagel RM: Nature 251:230, 1974
24. Doherty PC, Zinkernagel RM: Lancet i:1406, 1975

25. Zinkernagel RM, Doherty PC: Immunol Today 18:14, 1997

26. Schwartz R, Damashek W: Nature (London) 183:1682, 1959

27. Simonsen M: Ann NY Acad Sci USA 87:382, 1960

28. Starzl TE: In Experience in Renal Transplantation. Philadelphia: Saunders; 1964, p 168

29. Starzl TE: In Experience in Hepatic Transplantation. Philadelphia: Saunders; 1969, p 228

30. Steinman RM, Cohn ZA: J Exp Med 137:1142, 1973

31. Sterzl J, Silverstein AM: Adv Immunol 6:337, 1967

32. Dresser DW, Mitchison NA: Adv Immunol 8:129, 1968

33. Webb S, Morris C, Sprent J: Cell 63:1249, 1990

34. Moskophidis D, Lechner F, Pircher H, et al: Nature 362:758, 1993

35. Critchfield J, Racke M, Zuniga-Pflucker $J$, et al: Science 263:1139, 1994

36. Aichele P, Brduscha-Riem K, Zinkernagel RM, et al: J Exp Med 182:261, 1995

37. Qian S, Lu L, Fu F, et al: J Immunol 158:4654, 1997

38. Bishop AG, Sun J, Sheil AGR, et al: Transplantation 64:1377, 1997

39. Effros RB, Pawelec G: Immunol Today 18:450, 1997

40. Steinmuller D: Science $158: 127,1967$

41. Elkins WL, Guttmann RD: Science 159:1250, 1968

42. Hart DNJ, Winearls CG, Fabre JW: Transplantation 30:73, 1980

43. Lechler RI, Batchelor JR: J Exp Med 155:31, 1982

44. Billingham RE, Brent L, Medawar PB: Nature 172:603, 1953

45. Kundig TM, Bachmann MF, Oehen S, et al: Proc Natl Acad Sci USA 93:9716, 1996

46. Nemlander A, Soots A, Willebrand EV, et al: J Exp Med 156:1087, 1982

47. Larsen CP, Morris PJ, Austyn JM: J Exp Med 171:307, 1990

48. Demetris AJ, Qian S, Sun H, et al: Am J Pathol 138:609, 1991

49. Talmage DW, Dart G, Radovich J, et al: Science 191:385, 1976

50. Lafferty KJ, Prowse SJ, Simeonovic CJ: Ann Rev Immunol $1: 143,1983$

51. Zinkernagel RM, Hengartner H: Immunol Today 18:258, 1997

52. Terakura M, Murase N, Demetris AJ, et al: Transplantation (in press)

53. Ohashi PS, Oehen S, Buerki K, et al: Cell 65:305, 1991

54. Ohashi PS, Oehen S, Aichele P, et al: J Immunol 150:5185, 1993

55. Ehl S, Aichele P, Ramseier $\mathrm{H}$, et al: Nature Med (in press)

56. Murase N, Starzl TE, Tanabe M, et al: Transplantation $60: 158,1995$

57. Demetris AJ, Murase N, Starzl TE: Lancet 339:1611, 1992

58. Wood K, Sachs DH: Immunol Today 17:584, 1996

59. Starzl TE, Murase N, Demetris AJ, et al: Transplantation 62:703, 1996

60. Przepiorka D, Thomas ED, Durham DM, et al: Am J Clin Pathol 95:201, 1991

61. Matzinger P: Ann Rev Immunol 12:991, 1994

62. Ridge JP, Fuchs EJ, Matzinger P: Science 271:1723, 1996 